\title{
Study of the effect of cavitation upon the wheels of different types of materials for pump
}

\author{
Omar Khodjet Kesba a , Mustapha Kamel Mihoubi and Mohammed Bourkia \\ Laboratoire de Mobilisation et de Valorisation des Ressources en Eau (LMVR-Eau), École Nationale Supérieure \\ d'Hydraulique (ENSH), BP. 31, 09000 Blida, Algeria
}

Received 23 January 2013, Accepted 28 June 2013

\begin{abstract}
The study of the phenomenon of cavitation of centrifugal pumps remains of a great importance in the field of construction as well as in the field of installation of pumps in pumping stations. In fact, with the consequences it engenders: noise, vibration, erosion and loss of efficiency, it provokes, on the one hand, a progressive degradation of the performance of the machine and, on the other hand, an increase in the costs of the maintenance of installation (a compromise between the functioning period and cost of exploitation), in addition to the loss of efficiency of pumps and the resistance of different materials to the effects of the phenomenon of cavitation. Among the techniques and methods of protecting the parts of pumps is the cladding of the parts with composite plastic materials for the purpose of increasing the resistibility and protecting the parts from the effects of cavitation. Relevant to this, our work aims at analysing this problem with the intention of preserving the efficiency of a pump by limiting the effects of cavitation through an experimental study that has been realized in a laboratory. As such, wheels of different materials are tested under conditions of cavitation taking into consideration the three types of metals used in the manufacture of the wheel, and this regarding the study of resistibility of each material subject to the effects of the phenomenon aforementioned. Thus, this present work consists in experimentally studying the physical impact of cavitational erosion upon the hydrodynamic behavior and the performances of centrifugal pumps, and that affects the weight of different wheels. This phenomenon can be obtained only through measurement: loss of efficiency that can have repercussions for the characteristics of functioning as well as the mechanical behavior.
\end{abstract}

Key words: Pump / cavitation / performances / materials / wheel

\section{Introduction}

This study was undertaken through a limited collaboration of two organizations: National High School for Hydraulics (NHSH) and Pumps - Valves of Berrouaghia (POVAL) as it is applied to their respective fields of activity.

Users of pumps design their pumping installation by focusing on the characteristic curves "performances" that will be provided by the manufacturer and determined during pumping tests, and this is before being put into exploitation. First, the study consists of several realistic experiments to a large scale which permit to obtain reliable results in a wide range of variation of parameters for early anticipation of different erosions and validation of different technological techniques in order to ameliorate the functioning longevity of pumps in general.

\footnotetext{
${ }^{a}$ Corresponding author: okhodjet@yahoo.fr
}

The analysis that we present is relative to the physical experimental tests of the impact of the erosion of cavitation that permits, thanks to the control of the principal parameters of this phenomenon: rate of erosion, loss of efficiency (performances), type of materials. ..., to study the hydrodynamic conditions of the erosion of cavitation [1].

For a long period and until the 1980's, an important part of published works on the erosion of cavitation was devoted to the microscopic aspects of the phenomenon. Particularly, these works consist in carrying out tests of systematic erosion on a large number of materials subject to a given situation of cavitation. The starting point comprises the observation of the rear pockets of cavitation attached to blades of hydraulic machines which give off structures of vapour often organized around a whirlwind filaments, and that, by experience, proved particularly effective in terms of erosion: Selmi and Hutton (1983), Soyama, Kato and Oba (1992), Oba (1994), noting also a recent study by Sato and Kondo (1996) who were able 


\section{Nomenclature}

\begin{tabular}{|c|c|}
\hline ENSH & $\begin{array}{l}\text { École Nationale Supérieure d'Hydraulique } \\
\text { (National High School for Hydraulics) }\end{array}$ \\
\hline POVAL & $\begin{array}{l}\text { Pompes, Vannes d'Algérie, Pumps-- } \\
\text { Valves of Berrouaghia (Pumps, Valves } \\
\text { of Berroughia, Algeria) }\end{array}$ \\
\hline 40 NVA $150-5$ & $\begin{array}{l}\text { pump type horizontal-axis diameter of } \\
\text { suction } 40 \mathrm{~mm} \text {, diameter of the wheel of } \\
150 \mathrm{~mm} \text {, and thickness of the vane } 5 \mathrm{~mm}\end{array}$ \\
\hline (NPSH) & Net Positive Suction Head \\
\hline AGEP & $\begin{array}{l}\text { Agence des stations d'Epuration (Filter- } \\
\text { ing Station Agency) }\end{array}$ \\
\hline fENTP & $\begin{array}{l}\text { École Nationale des Travaux Publics } \\
\text { (National School of Public Works) }\end{array}$ \\
\hline ONID & $\begin{array}{l}\text { Office National d'Irrigation et de Drainage } \\
\text { (Irrigation and Draining National Office) }\end{array}$ \\
\hline
\end{tabular}

to observe in situ axial or radial implosions of cavitating whirlwinds and measure the forces exerted on the partitions of the flow. Pertinent to this, the impact of erosion of cavitation is defined and studied according to the parameters of erosion and the ability of materials (cast iron, aluminum, and bronze) in absorbing the energy of cavitation impact [2-4].

The most currently useful materials in the construction of pumps are cast iron, steel, stainless steel, and copper alloys. For particular cases, especially in oil and chemical industries, nickel alloys, aluminum, lead, titanium... etc, as well as non-metallic materials, are often used.

We know from the double approach experimental and numerical, that these two last mechanisms are able to engender very high pressures (hardly measurable as we will see later).

\section{Experimental design}

\subsection{Construction of the test model}

Our test model is a closed circuit: suction and suppression are made in the same water tank of the following dimensions: length $04 \mathrm{~m}$, width $02 \mathrm{~m}$, depth $02 \mathrm{~m}$.

A test model is designed in order to provoke cavitation on the pump with the different types of materials of the wheel. We determine the type of the wheel material whose erosion is lesser and which presents good characteristics of the pump after cavitation (Fig. 1).

\subsection{Materials}

In general, the characteristics of the pump (lifting height, delivery rate, power absorbed and performance), are provided by the manufacturer during the tests. In Table 1, they are determined under certain conditions and according to certain installations (Fig. 2).

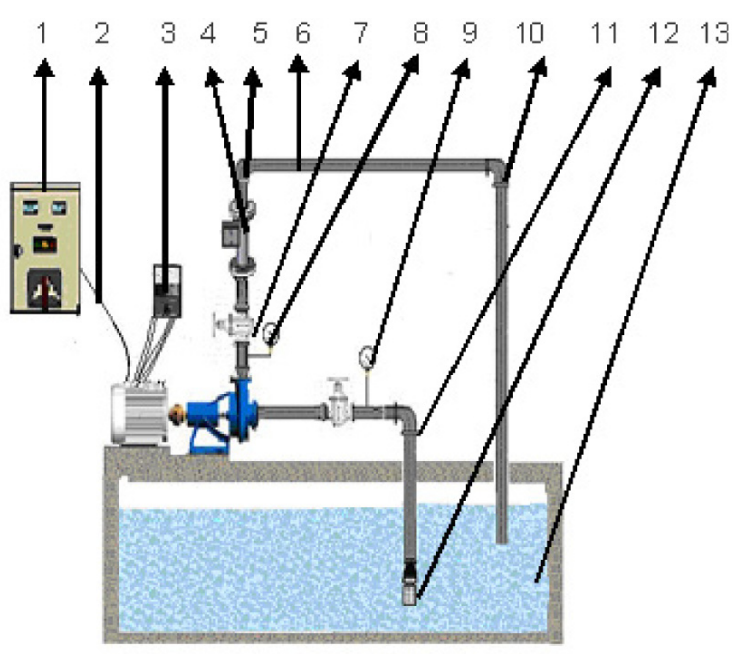

Fig. 1. Scheme of the test model for studying the effects of cavitation.

Key:

1 - electric cabinet;

2 - electric wires;

3 - wattmeter;

4 - counter;

5 - elbow $90^{\circ}$ of diameter $40 \mathrm{~mm}$;

6 - discharge pipe;

7 - valve stop mode $40 \mathrm{~mm}$;

8 - manometer;

9 - vacumeter;

10 - elbow $90^{\circ}$ of diameter $50 \mathrm{~mm}$;

11 - suction valve $50 \mathrm{~mm}$;

12 - foot valve;

13 - water tank.

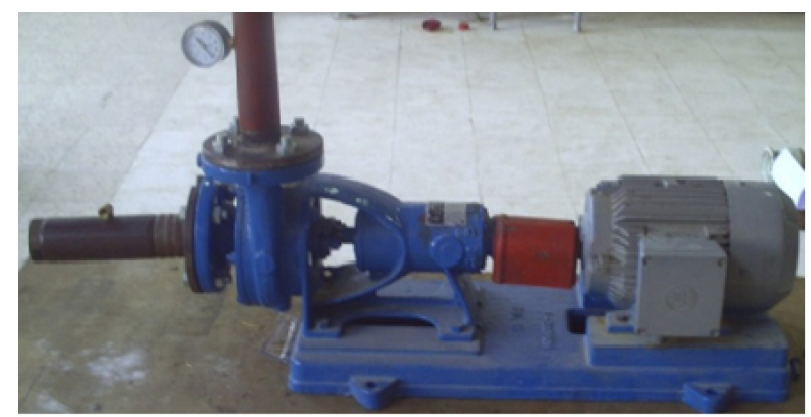

Fig. 2. Centrifugal pump of POVAL, type NVA 150-5 [8].

During the experimentation of our pump (20 h of functioning) under the effect of cavitation by strangulation of the suction, the form of the tests is filled in (variation of flow). By using the formulas, all the parameters are going to be calculated in order to draw characteristic curves and interpret the results.

Our work consists in studying the effects of the phenomenon of cavitation upon the erosion of a wheel of the pump manufactured by the company POVAL (pump 40NVA). The experiment is carried out on three types of materials used in manufacturing the wheel (Fig. 3). 
Table 1. Characteristics of the pump (POVAL) Berrouaghia, 2003

\begin{tabular}{cc}
\hline Characteristics & Limits \\
\hline Flow $\left(\mathrm{m}^{3} \cdot \mathrm{h}^{-1}\right)$ & 18 \\
Lifting height $(\mathrm{m})$ & 23.5 \\
Rotation speed & 2900 \\
(turns.min $\left.{ }^{-1}\right)$ & \\
Temperature of & $80{ }^{\circ} \mathrm{C}$ with $2 \%$ by \\
the liquid & mechanical addictions and \\
& a granulometry of $0.5 \mathrm{~mm}$ \\
NPSH $(\mathrm{m})$ & 2.7 \\
Engine power $(\mathrm{kW})$ & 2.2 \\
Weight of the pump $(\mathrm{kg})$ & 23.1 \\
Optimum output $(\%)$ & 61 \\
Variation of proper & $16.2-19.8$ \\
functioning $\left(\mathrm{m}^{3} \cdot \mathrm{h}^{-1}\right)$ & \\
\hline
\end{tabular}

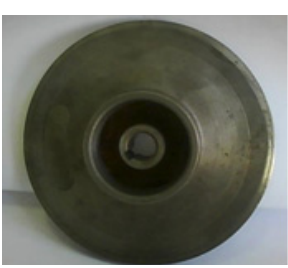

a) Cast iron

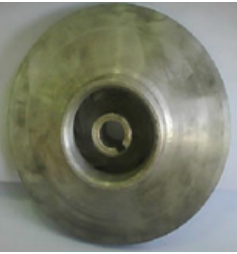

b) Aluminium

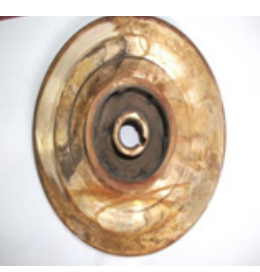

c) Bronze
Fig. 3. Three identical wheels made of different materials.

\subsubsection{Wheel in cast iron}

Cast iron represents all alloys met for casting. It is different from other alloys in its excellent malleability. The fusion temperature of cast iron goes from $1135{ }^{\circ} \mathrm{C}$ to $1350^{\circ} \mathrm{C}$ according to the percentage of carbon and silicon that it contains.

The principal qualities of white cast iron are funded on the following features: excellent resistance to erosion and to abrasion, good aspect and excellent malleability. Their main defects are: difficult to be machined, hard and fragile, and heavy $[2,5]$.

\subsubsection{Wheel in aluminium}

Aluminum has a density of 2.7, around three times weaker than that of steel or copper. It is malleable, ductile and easily machined and molded. It possesses excellent resistance to corrosion and a great longevity. It is also paramagnetic and it does not cause sparks. It is the second metal the most malleable and the sixth the most ductile and very light.

\subsubsection{Wheel in bronze}

Bronze is the generic name of the alloys of copper and tin. Bronze is normally composed of more than $60 \%$ of copper and a variable proportion of tin, besides variable proportions of aluminum, lead, beryllium, manganese and

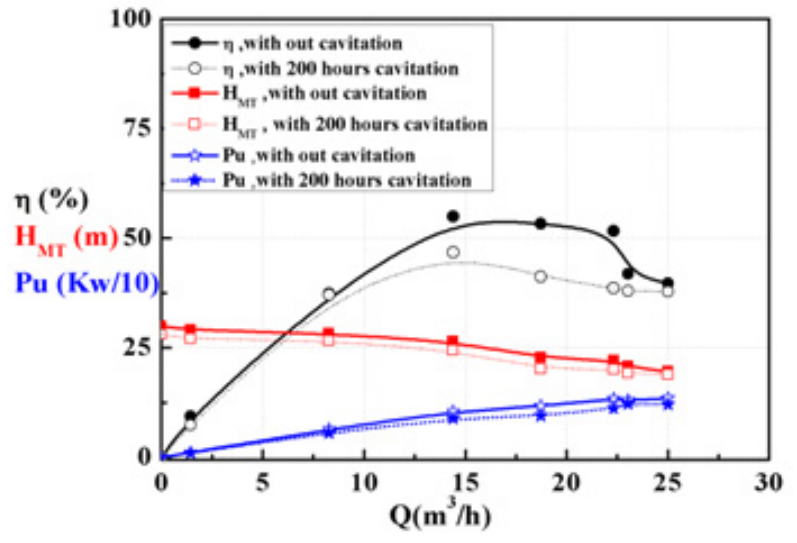

Fig. 4. Characteristic curves of the pump functioning with a new wheel in cast iron and $200 \mathrm{~h}$ of functioning under the effects of cavitation.

tungsten, and a small amount of silicon and phosphorus, but no zinc in notable quantities; yet, it resists to erosion and corrosion [6].

\subsection{Calculating method}

The tests of our work comprise three main lines:

- The first consists in drawing the characteristic curves of the pump.

- The second consists in demonstrating the wheel, measuring its weight and in taking a photograph during the twenty hours of operation under the effects of cavitation by strangulation [7].

- The same work is produced for the three wheels of different materials: cast iron, aluminum, bronze.

- After putting into effect the tests as we have seen throughout the handling of the operation, and from the application of the formulas for the calculation of different parameters, we can to determine the results as well as to present them in graphs.

\section{Results and interpretation}

From Figures 4-6, which represent the different curves, we notice a loss of efficiency (performances) of our pump (pump 40NVA), for both of the lifting height and performance, and this for a functioning period of $200 \mathrm{~h}$ under the effect of cavitation.

- A decrease in performance of: $8.15 \%$, for the pump functioning under the effect of cavitation and with a wheel in cast iron.

- A decrease in performance of: $15.18 \%$, for the pump functioning under the effect of cavitation and with a wheel in aluminum.

- A decrease in performance of: $5.31 \%$, for the pump functioning under the effect of cavitation and with a wheel in bronze.

- Relevant to these results, we can introduce the following comments. 


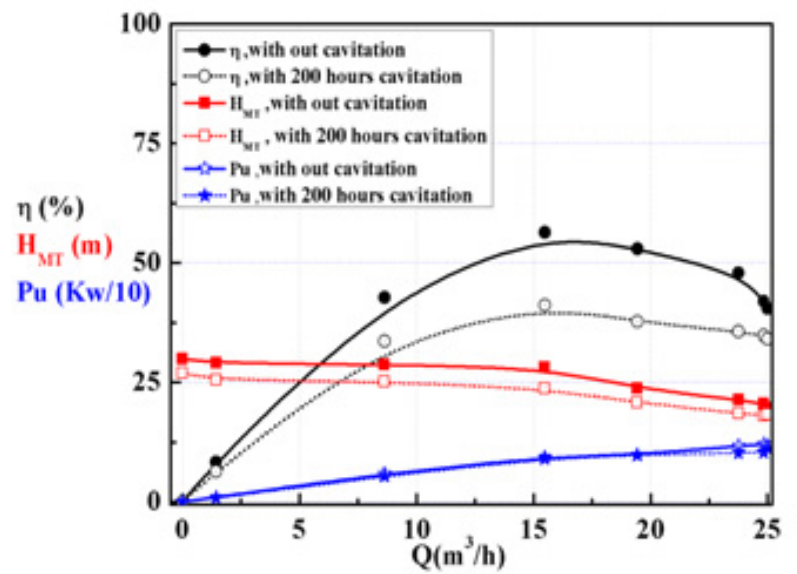

Fig. 5. Characteristic curves of the pump functioning with a new wheel in aluminum and $200 \mathrm{~h}$ of functioning under the effects of cavitation.

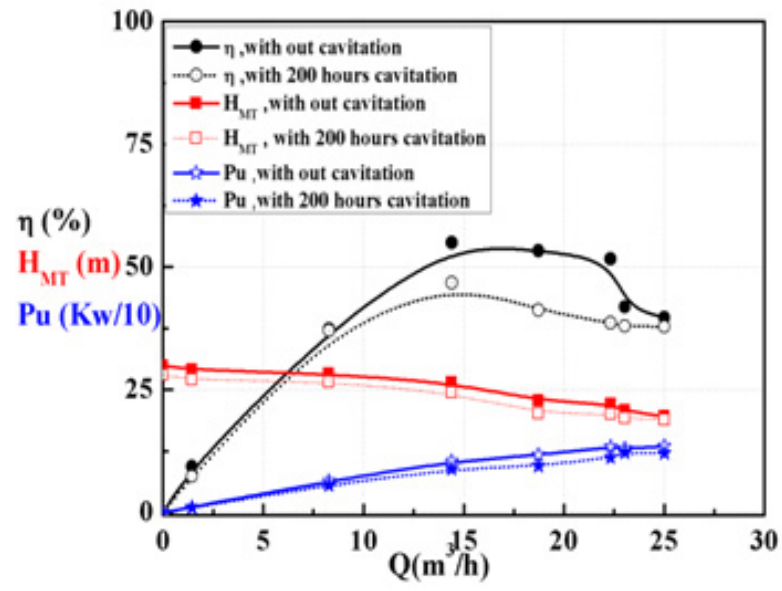

Fig. 6. Characteristic curves of the pump functioning with a new wheel in bronze and $200 \mathrm{~h}$ of functioning under the effects of cavitation.

Bronze resists better than aluminum and cast iron to the effects of cavitation. A pump functioning with a wheel in bronze presents the least decrease in performance. Aluminum is the weakest metal resisting to the effects of cavitation in spite of the good performances revealed at the initial state (new pump).

Cast iron shows the average between bronze and aluminum.

From the reading of the graphs (Figs. 7-9), we remark that the pump functioning with a wheel in aluminum presents the best performance at the initial state. However, later and during the two hundred hours of functioning, under the effect of cavitation, we notice an important decrease of weight, $(0.29 \%)$.

In the case of the functioning of the pump with a wheel in bronze which presents a weak weight at the initial state and a decrease of $(0.008 \%)$, after the two hundred hours of functioning under the effects of cavitation. For the nominal rate, we remark that there is stability during the two hundred hours.

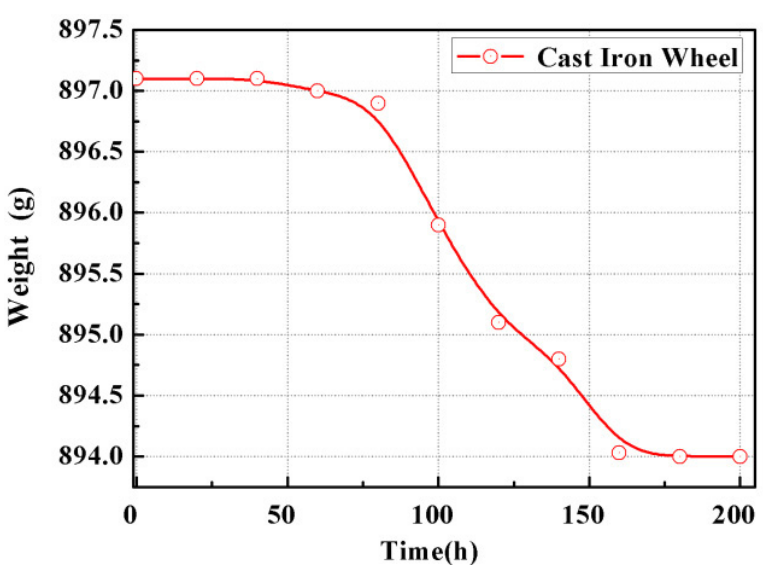

Fig. 7. Curve of the variation of weight of the wheel in cast iron according to functioning time.

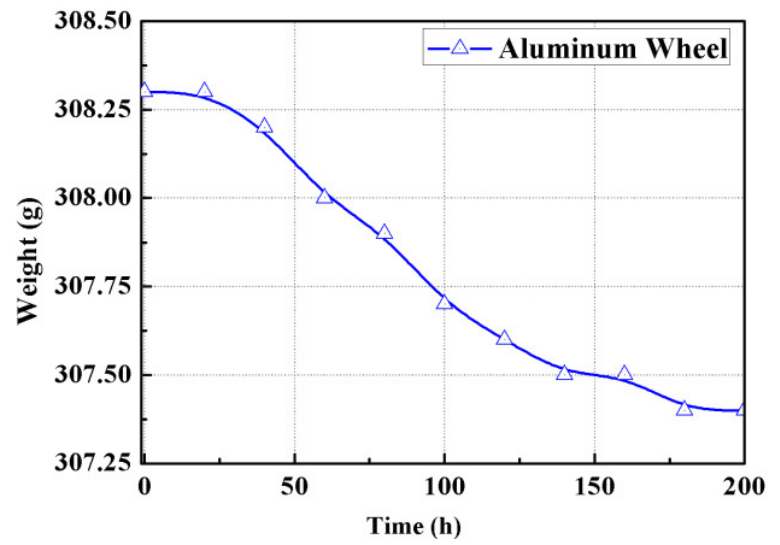

Fig. 8. Curve of the variation of weight of the wheel in aluminum according to functioning time.

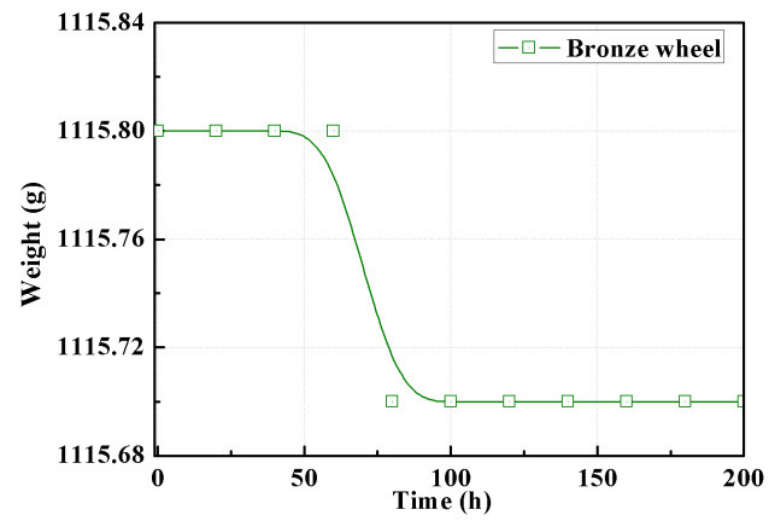

Fig. 9. Curve of the variation of the weight of the wheel in bronze according to functioning time.

Concerning the functioning of the pump with a wheel in cast iron which presents a good performance at the initial state and a decrease of $(0.34 \%)$, after the two hundred hours of functioning under the effects of cavitation, for the nominal height, we notice a medium decrease in comparison to that of the pump functioning with a wheel 
Table 2. Decrease in the mass of the wheels according to functioning time.

\begin{tabular}{|c|c|c|c|c|c|c|c|}
\hline & & \multicolumn{2}{|c|}{ Period (h) } & 00 & 20 & 40 & 60 \\
\hline \multirow{3}{*}{\multicolumn{2}{|c|}{ Mass of the wheel $(\mathrm{g})$}} & \multirow{3}{*}{\multicolumn{2}{|c|}{$\begin{array}{c}\text { Wheel in cast iron } \\
\text { Wheel in aluminium } \\
\text { Wheel in bronze }\end{array}$}} & 897.1 & \multirow{2}{*}{$\begin{array}{l}897.1 \\
308.3\end{array}$} & 897.1 & 897.0 \\
\hline & & & & 308.3 & & 308.2 & 308.0 \\
\hline & & & & 1115.8 & 1115.8 & 1115.8 & 1115.8 \\
\hline 80 & 100 & 120 & 140 & 160 & & 30 & 200 \\
\hline 896.9 & 895.9 & 895.1 & 894.8 & 894.03 & & 4.0 & 894.0 \\
\hline 307.9 & 307.7 & 307.6 & 307.5 & 307.5 & & 7.4 & 307.4 \\
\hline 1115.7 & 1115.7 & 1115.7 & 1115.7 & 1115.7 & & 5.7 & 1115.7 \\
\hline
\end{tabular}

in aluminum. For the nominal rate, we note that there is stability during the two hundred hours.

\section{Interpretation and discussions}

Hydraulic performances of the wheels are compared in Figure 10.

- Cast iron shows the average between bronze and aluminum, as showed by the curves of the variation of the lifting height of the pump 40 NVA according to performance during the two hundred hours of functioning under the effects of cavitation (wheel in cast iron).

- Aluminum is the weakest metal resisting to the effects of cavitation despite good performance revealed at the initial state (new pump or zero hour of functioning under the effects of cavitation).

- Bronze resists better than the aluminum and cast iron to the effects of cavitation. A pump functioning with a wheel in bronze presents the least decrease of performances.

\section{Conclusion}

As far as we are concerned, we have realized throughout this study a series of tests of materials under the effect of cavitation with the available means looking for a response to our expectations, namely the cavitational study and the impact of some of its effects.

On the light of the experimental results obtained and knowing that this work was made through the collaboration of National High School for Hydraulics and POVAL, so it can have continuity as an objective, with a view to improve the experimental results and better understand the phenomenon of cavitation and later reduce the effects of mechanical damage on the pump. To finally arrive at ameliorating the performances of a pump with a wheel of well chosen materials, we propose the following recommendations [9]:

1. The installation of pressure measuring apparatus (monometer and vacumeter) must be at a sufficient distance, so that it does not affect the reading of the apparatus.
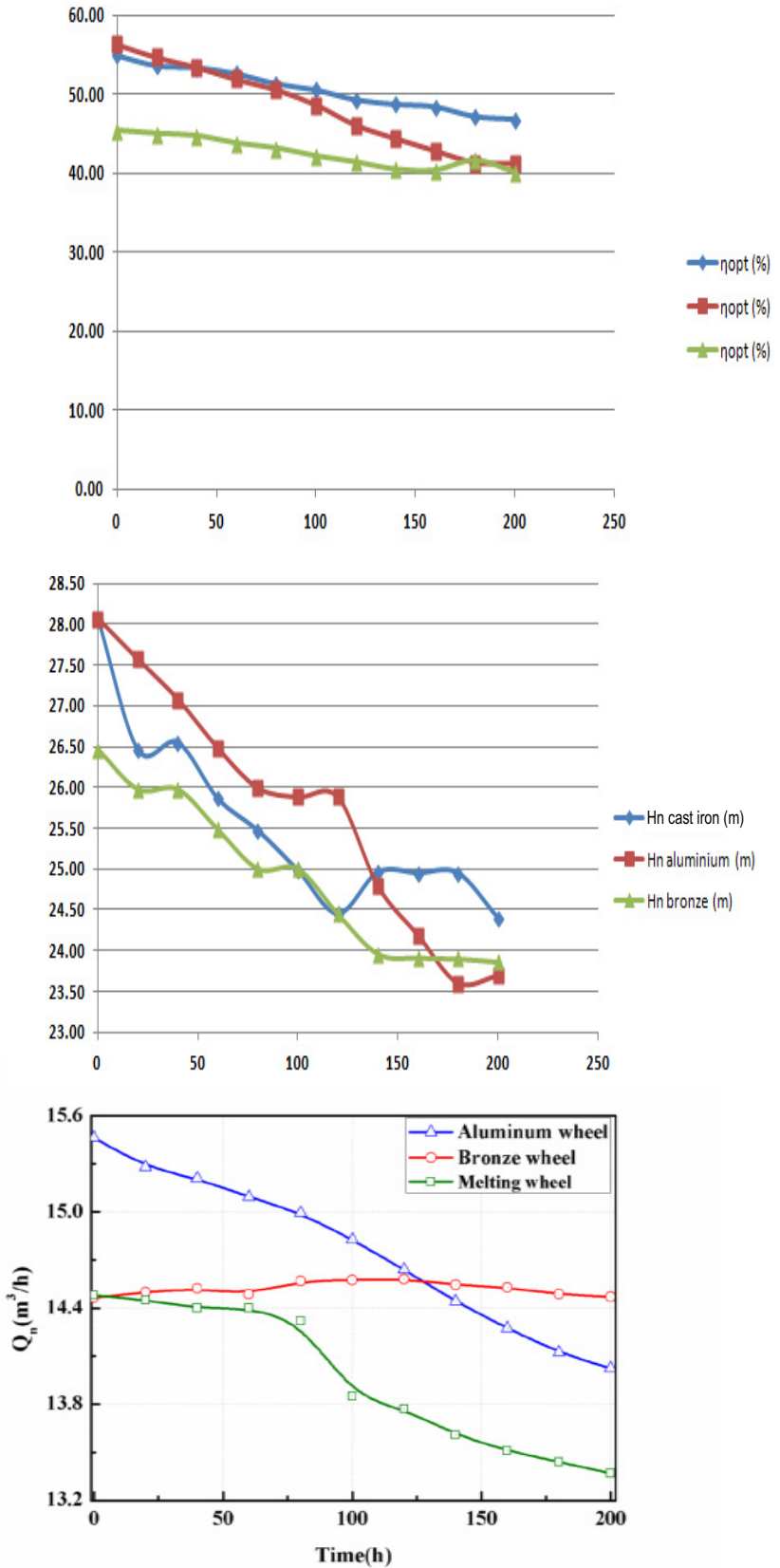

Fig. 10. Curves of the variation of optimum performance, the variation of nominal height and the variation of nominal rate according to the functioning of the pump under the effects of cavitation. 
2. Sudden changes of direction are not recommended and also all obstacles are detrimental to proper functioning of pump indeed whirlwinds of vortex can be created and thus the pump is disrupted.

3. Use slow convergents to get a good flow.

4. It is necessary to forced connections between the pipes and during the assembly of the wheel into the casing must be avoided because that can provoke a lack of parallelism of the flanges, and will result in friction of the wheel or on the casing [10].

\section{References}

[1] A.L. Mular, D.N. Halbe, J.D. Barratt, Believed that abrasive wear for given slurry increases by the velocity to a power of somewhere between 2 and 3.5 (Wiedenroth 1984; Rao and Buckly 1984), 2002, p. 2422

[2] C. Bathia, J.P. Baillou, La fatigue des matériaux et des structures, Collection Université de Compiègne, 1980, p. 547

[3] R. Canavellis, J.F. Lapray, R. Rey, Étude d'un critère de fiabilité vis à vis de l'érosion par cavitation dans les pompes, Symposium Montréal, 1986
[4] M.A. Domingez-Cortazar, Le CAVERMOD: modèle physique de l'érosion de cavitation: qualification expérimentale et numérique, Thèse de Doctorat, INPG, Grenoble, France, 1994, p. 225

[5] S. Lavigne, A. Retailleau, J. Woillez, Measurement of the aggressivity of erosive cavitating flows by a technique of pits analysis. Application to a method of prediction of erosion, Proc. Int. Symp. Cavitation CAV95, 1995

[6] J. Wiley, Hand book of materials selections, Edit Mayer kutz, New York, 2002, pp. 550-575

[7] O. Khodjet-Kesba, Influence de l'érosion cavitationnelle sur les optimums de fonctionnement des systèmes de pompage, Revue Technique et Scientifique des collaborateurs de l'ENSH, l'A.G.E.P., l'O.N.I.D., 1996 p. 38

[8] Catalogue des pompes de POVAL, 2004

[9] G. Chahine, Bubble Dynamics, in Research and Development in Applied Sciences, 2013

[10] S.H. Parker, H.K. Suh, C.S. Lee, Effect of cavitating flow on the flow and fuel atomisation characteristics of biodiesel ans diesel fuels, Energy and Fuels 22 (2008) 605-613 